\title{
METODE PICTURE AND PICTURE KARTU GRAFIK FUNGSI SEBAGAI MEDIA PEMBELAJARAN MATEMATIKA SISWA KELAS IX MADRASAH TSANAWIYAH NEGERI 1 LANGKAT
}

\author{
Ahmad Yuti \\ Surel: hmdyuti@gmail.com
}

\begin{abstract}
The results of classroom action research (PTK) show that the value acquisition has increased very well, where the results of this study use quantitative data analysis with 32 respondents from class IX-1 as samples, while data management uses the product moment formula and the $t$ test. Picture And Picture function graph card as a medium for learning mathematics for grade IX students at Madrasah Tsanawiyah Negeri 1 Langkat, it can improve student learning outcomes in mathematics, this can be seen from the results of daily exams, the correlation of arithmetic results in the first cycle between pre-test scores (pretest) with the block I test score of 0.798, and the t test of 7.262, and the correlation of the calculated results in the second cycle between the block I test score and the block II test score of 0.899, and the t test of 11.26, it can also increase student activity in mathematics This can be seen from the activity of students in participating in the mathematics learning process with a value of $88 \%$ attendance at the beginning of the action, increased to $95 \%$ attendance in the first cycle, and increased again to $100 \%$ attendance in the second cycle, because students enjoy making and playing graphic cards. Function, so that it is fun for students in learning mathematics.
\end{abstract}

Keywords: Picture and Picture Method, Function Graphic Card, Mathematics Learning Media

\begin{abstract}
ABSTRAK
Hasil penelitian tindakan kelas (PTK) menunjukkan bahwa perolehan nilai terjadi peningkatan yang sangat baik, dimana hasil penelitian ini menggunakan jenis analisis data secara kuantitatif dengan 32 responden dari kelas IX-1 sebagai sampel, sementara pengelolaan data memakai rumus product moment dan uji t. Picture And Picture kartu grafik fungsi sebagai media pembelajaran matematika siswa kelas IX Madrasah Tsanawiyah Negeri 1 Langkat, dapat meningkatkan hasil belajar siswa pada pelajaran matematika, hal ini dilihat dari hasil ujian harian, korelasi hasil hitung pada siklus pertama antara nilai pre tes (tes awal) dengan nilai ujian blok I sebesar 0,798, dan uji t sebesar 7,262, serta korelasi hasil hitung pada siklus kedua antara nilai ujian blok I dengan nilai ujian blok II sebesar 0,899 , dan uji t sebesar 11,26 , juga dapat meningkatkan aktivitas siswa pada pelajaran matematika, hal ini dilihat dari keaktivan siswa dalam mengikuti proses pembelajaran matematika dengan nilai $88 \%$ kehadiran pada awal tindakan, meningkat menjadi $95 \%$ kehadiran pada siklus pertama, dan meningkat lagi menjadi $100 \%$ kehadiran pada siklus kedua, karena siswa senang dalam membuat dan memainkan kartu Grafik Fungsi, sehingga menyenangkan siswa dalam belajar matematika.
\end{abstract}

Kata Kunci : Metode Picture And Picture, Kartu Grafik Fungsi, Media Pembelajaran Matematika 


\section{PENDAHULUAN}

Metode picture and picture adalah suatu model belajar yang menggunakan gambar dan dipasangkan/diurutkan menjadi urutan logis. Model pembelajaran ini mengandalkan gambar sebagai media dalam proses pembelajaran. Gambargambar ini menjadi faktor utama dalam proses pembelajaran. Sehingga sebelum proses pembelajaran guru sudah menyiapkan gambar yang akan ditampil kan baik dalam bentuk kartu atau dalam bentuk carta dalam ukuran besar. Model pembelajaran picture and picture merupakan salah satu model pembelajaran kooperatif. Model pembelajaran picture and picture ini dapat digunakan dalam berbagai mata pelajaran dan tentunya dengan kemasan dan kreatifitas guru. Sejak di populerkan sekitar tahun 2002, model pembelajaran ini mulai menyebar di kalangan guru di Indonesia. Dengan menggunakan model pembelajaran tertentu, maka pembelajaran menjadi menyenangkan. Selama ini hanya guru sebagai aktor di depan kelas, dan seolah-olah gurulah sebagai satusatunya sumber belajar. Model pembelajaran picture and picture merupakan sebuah model dimana guru menggunakan alat bantu atau media gambar untuk menerang kan sebuah materi atau memfasilitasi siswa untuk aktif belajar. Dengan menggunakan alat bantu atau media gambar, diharapkan siswa mampu mengikuti pelajaran dengan fokus yang baik dan dalam kondisi yang menyenangkan. Sehingga apapun pesan yang disampaikan bisa diterima dengan baik dan mampu meresap dalam hati, serta dapat diingat kembali. Pembelajaran ini memiliki ciri aktif, inovatif, kreatif, dan menyenangkan. inovatif setiap pembelajaran harus memberikan sesuatu yang baru, berbeda dan selalu menarik minat peserta didik. Dan Kreatif, setiap pembelajarnya harus menimbulkan minat kepada peserta didik untuk menghasilkan sesuatu atau dapat menyelesaikan suatu masa lah dengan menggunakan metode, teknik atau cara yang dikuasai oleh siswa itu sendiri yang diperoleh dari proses pembelajaran.

Gambar yang baik digunakan dalam pembelajaran adalah gambar yang sesuai dengan tujuan pembelajaran. Oleh karena itu, terdapat tiga syarat yang harus dipenuhi yaitu: Harus otentik, Gambar tersebut harus lah secara jujur melukiskan situasi seperti melihat benda sebenarnya, Sederhana, Komposisi hendaknya cukup jelas dalam menunjukkkan poin-poin pokok yang terdapat pada gambar, Memiliki Nilai Seni, Sebagai media yang baik, gambar hendaklah bagus dari sudut seni.

Penelitian ini memiliki tujuan sebagai berikut: untuk mengetahui Metode Picture And Picture kartu grafik fungsi sebagai media pembelajaran matematika dapat meningkatkan hasil belajar matematika dan aktivitas siswa dalam belajar matematika di kelas IX Madrasah Tsanawiyah Negeri 1 Langkat. 


\section{METODE PENELITIAN}

Prosedur ini melibatkan siswa kelas IX di Madrasah Tsanawiyah Negeri 1 Langkat Semester Ganjil yang beralamat di jalan Pembangunan no.3 desa Pekubuan kecamatan Tanjung Pura kabupaten Langkat Sumatera Utara, DAN berjumlah 32 orang. Penelitian ini dilakukan dua siklus, metode Picture and Picture adalah suatu model pembelajaran dengan menggunakan media gambar. Dalam oprasionalnya gambar-gambar dipasangkan satu sama lain atau bisa jadi di urutkan menjadi urutan yang logis, dengan langkah-langkah sebagai berikut :

Pertama, Guru menyampaikan kompetensi yang ingin dicapai . Peserta didik menerima informasi tentang kompetensi yang ingin dicapai. Di langkah ini guru diharapkan untuk menyampaikan apakah yang menjadi Kompetensi Dasar mata pelajaran yang bersangkutan. Dengan demikian maka siswa dapat mengukur sampai sejauh mana yang harus dikuasainya. disamping itu guru juga harus menyampaikan indikator-indikator ketercapaian KD, sehingga sampai dimana KKM yang telah ditetapkan dapat dicapai oleh peserta didik.

Kedua, menyajikan materi sebagai pengantar. Peserta didik menerima materi sebagai pengantar, penyajian materi sebagai pengantar sesuatu yang sangat penting, dari sini guru memberikan momentum permulaan pembelajaran. Kesuksesan dalam proses pembelajaran dapat dimulai dari sini. Karena guru dapat memberikan motivasi yang menarik perhatian siswa yang selama ini belum siap. Dengan motivasi dan teknik yang baik dalam pemberian materi akan menarik minat siswa untuk belajar lebih jauh tentang materi yang dipelajari.

Ketiga, guru menunjukan/ memperlihatkan gambar-gambar kegiatan yang berkaitan dengan materi. Peserta didik menerima gambar-gambar berkaitan dengan materi. Dalam proses penyajian materi, guru mengajar siswa ikut terlibat aktif dalam proses pembelajaran dengan mengamati setiap gambar yang ditun jukkan oleh guru atau oleh temannya. Dengan Picture atau gambar kita akan menghemat energi kita dan siswa akan lebih mudah memahami materi yang diajarkan. Dalam perkembangakan selanjutnya sebagai guru dapat memodifikasikan gambar atau mengganti gambar dengan video atau demontrasi yang kegiatan tertentu.

Keempat, Guru menunjuk/ memanggil siswa secara bergantian memasang/mengurutkan gambargambar menjadi urutan yang logis. Peserta didik secara bergantian mengurutkan gambar-gambar menjadi urutan yang logis. Di langkah ini guru harus dapat melakukan inovasi, karena penunjukan secara langsung kadang kurang efektif dan siswa merasa terhukum. Salah satu cara adalah dengan undian, sehingga siswa merasa memang harus menjalankan tugas yang harus diberikan. Gambar-gambar yang 
sudah ada diminta oleh siswa untuk diurutan, dibuat, atau dimodifikasi.

Kelima, Guru menanyakan alasan/dasar pemikiran urutan gambar tersebut. Peserta didik menyampaikan alasan/dasar pemikiran urutan gambar tersebut. Setelah itu ajaklah siswa menemukan rumus, tinggi, jalan cerita, atau tuntutan KD dengan indikator yang akan dicapai. Ajaklah sebanyak-banyaknya peran siswa dan teman yang lain untuk membantu sehingga proses diskusi dalam PBM (Proses Belajar Mengajar) semakin menarik.

Keenam, dari alasan/urutan gam bar tersebut guru memulai menanamkan konsep/materi sesuai dengan kompetensi yang ingin dicapai. Peserta didik menerima penguatan materi dan kesimpulan sesuai dengan kompetensi yang akan dicapai.

Ketujuh, Kesimpulan/ rangkuman, Peserta didik menyampaikan kesimpulan, di akhir pembelajaran, guru bersama siswa mengambil ke- simpulan sebagai penguatan materi pelajaran.

\section{HASIL PENELITIAN DAN PEMBAHASAN}

Cara pembuatan gambar kartu grafik fungsi kuadrat adalah satu set kartu ini jumlahnya harus 36 lembar, untuk itu kita perlu membuat fungsi pemetaan yang terdiri dari 1 garfik fungsi memetakan ke 6 syarat fungsi, karena terdapat 6 macam grafik fungsi, maka terdapat 36 pemetaan yang terjadi. Berikut ini contoh pembuatan kartu dengan standar kompetensi: Memecahkan masalah yang berkaitan dengan fungsi, persamaan dan fungsi kuadrat serta pertidaksamaan kuadrat. Dan Indikato : memasangkan grafik fungsi ke syarat fungsi dan melatih keterampilan siswa tentang grafik fungsi kuadrat dan sifat-sifat aljabarnya. Cara pembuatan kartu grafik fungsi kuadrat dapat dilihat pada gambar berikut ini :
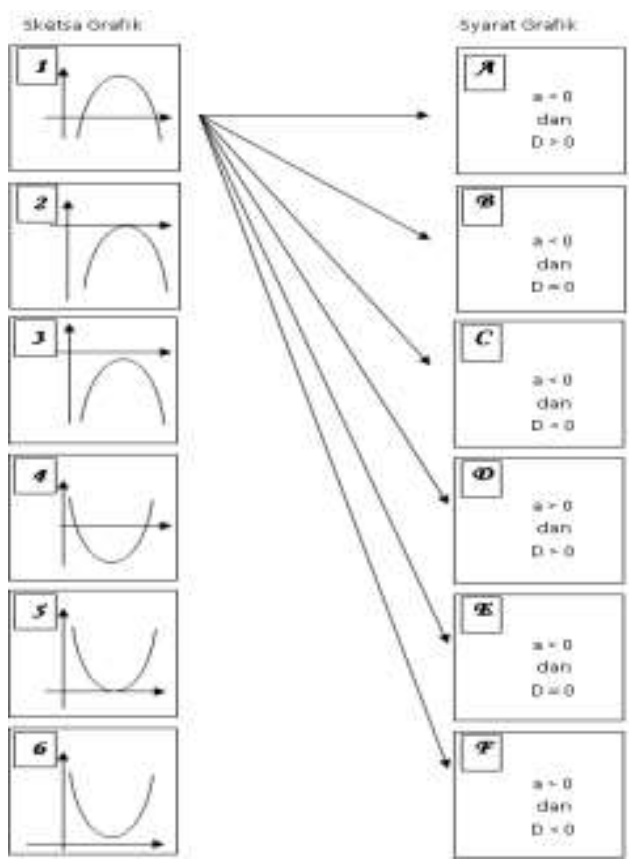

\section{Gambar 1. Kartu Grafik Fungsi Kuadrat}

Cara Penggunaan Bermain Kartu. Cara pertama: Permainan kartu untuk 2, 3, atau 4 pemain, Kocok kartu, dan bagikan ke tiap-tiap pemain 4 kartu, Buka 1 kartu dari tumpukan kartu sisa di atas meja, Secara bergantian pemain menyambung kartu dimulai dari yang terbuka tadi dengan syarat: grafik disambung dengan syarat yang sesuai, Bila pada gilirannya, pemain tidak 
memiliki kartu yang sesuai, maka ia harus mengambil dari tumpukan kartu sisa hingga memperoleh kartu yang sesuai, Bila kartu sisa habis dan pemain tidak dapat melangkah (karena tidak memiliki kartu yang sesuai) maka gilirannya diambil alih oleh pemain yang berikutnya, Pemenang adalah pemain yang pertama kali dapat menghabiskan kartu yang dipegangnya, atau yang memiliki kartu paling sedikit.

Cara kedua; Permainan kartu untuk 2, 3, atau 4 pemain, Kocok kartu, dan bagikan ke tiap-tiap pemain hingga kartu habis terbagi, Undilah giliran melangkah, lalu pemain pertama membuka 1 kartu di atas meja, Secara bergantian pemain lain menyambung kartu, dimulai dari yang terbuka tadi dengan syarat: grafik disambung dengan syarat yang sesuai. Bila pada gilirannya, seorang pemain tidak dapat melangkah (karena tidak memiliki kartu yang sesuai) maka gilirannya diambil alih oleh pemain yang berikutnya, Pemenang adalah pemain yang pertama kali dapat menghabiskan kartu yang dipegangnya, atau yang memiliki kartu paling sedikit.

Cara ketiga ; Permainan kartu untuk 2, 3, atau 4 pemain. Kocok kartu, dan bagikan ke tiap-tiap pemain 4 kartu. Buka 1 kartu dari tumpukan kartu sisa. Secara bergantian pemain menyambung kartu dimulai dari yang terbuka tadi dengan syarat : grafik disambung dengan syarat yang sesuai, Setiap menurunkan satu kartu, pemain mengambil 1 kartu dari tumpukan kartu sisa. Apabila tumpukan kartu sisa habis dan pemain tidak memiliki kartu yang sesuai, maka gilirannya dilanjutkan oleh pemain berikutnya. Pemenang adalah pemain yang pertama kali dapat menghabiskan kartu yang dipegangnya, atau yang memiliki kartu paling sedikit. Contoh permainannya seperti domino :

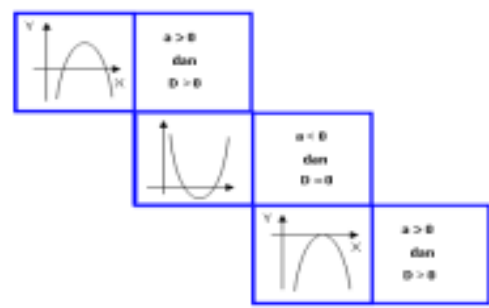

Gambar 2. Grafik Fungsi Kuadrat

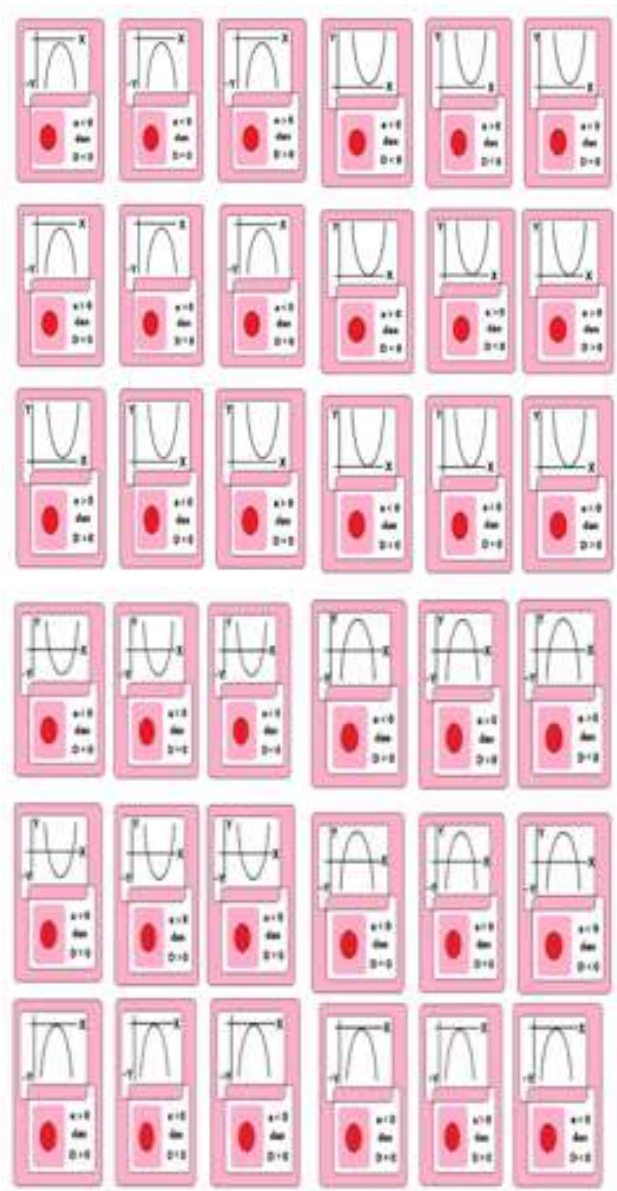

Gambar 3. Kartu Grafik fungsi 
Sebelum gambar kartu grafik fungsi dibuat dengan menggunakan komputer, guru memberikan pengarahan kepada siswa untuk membuat kartu tersebut memakai spidol di atas kertas kartun, setelah itu dicoba bermain sesuai dengan permainan kartu domino dan kelompok yang telah ditetapkan.

Selanjutnya, guru mengarahkan agar siswa dapat membuat gambar kartu grafik fungsi tersebut dengan menggunakan komputer, agar gambarnya terlihat bagus dan rapi.

\section{Pembahasan}

Hasil permainan gambar grafik fungsi tersebut ditulis oleh guru berbentuk angka atau nilai dan dicoba dengan menyelesaikan soal-soal ujian harian (ujian blok) berdasarkan tes soal yang diberikan oleh guru yaitu tes awal (pre tes) sebelum tindakan atau kegiatan penelitian dilakukan, dan tes pada siklus pertama setelah kegiatan penelitian tindakan kelas, serta tes akhir atau tes pada siklus kedua setelah kegiatan penelitian tindakan kelas dilaksanakan. Hasilnya dapat dilihat pada tabel berikut ini :

Tabel 1. Rangkuman Perhitungan Nilai Rata-Rata dan Simpangan Baku Tentang Hasil Belajar Matematika Siswa MTsN 1 Langkat

\begin{tabular}{|c|c|c|c|c|c|c|c|c|c|c|c|c|c|c|c|}
\hline No & $\begin{array}{l}\text { Test } \\
\text { Awal }\end{array}$ & & & $\begin{array}{c}\text { Test } \\
\text { Sildus I }\end{array}$ & & & $\begin{array}{c}\text { Test } \\
\text { Siklus II }\end{array}$ & & & $\mathrm{xx}$ & $Y Y$ & $X Y$ & $x x$ & $Y Y$ & $X Y$ \\
\hline 1 & 80 & 4,781 & 22,858 & 82 & 4 & 16 & \begin{tabular}{|l|}
86 \\
\end{tabular} & 5,469 & 29,91 & 6400 & 6724 & 6560 & 6724 & 7396 & 7052 \\
\hline 2 & 80 & 4,781 & 22,858 & 83 & 5 & 25 & 85 & 4,469 & 19,97 & 6400 & 6889 & 6640 & 6889 & 7225 & 7055 \\
\hline 3 & 84 & 8.781 & 77,106 & 86 & 8 & 64 & 88 & 7,469 & 55,79 & 7056 & 7396 & 7224 & 7396 & 7744 & 7568 \\
\hline 4 & 75 & $-0,219$ & 0,04796 & 79 & I & 1 & 83 & 2,469 & 6,096 & 5625 & 6241 & 5925 & 6241 & 6889 & 6557 \\
\hline 5 & 80 & 4,781 & 22,858 & 82 & 4 & 16 & 86 & 5,469 & 29,91 & 6400 & 6724 & 6560 & 6724 & 7396 & 7052 \\
\hline 6 & 86 & 10,781 & 116,23 & 88 & 10 & 100 & 90 & 9,469 & 89,66 & 7396 & 7744 & 7568 & 7744 & 8100 & 7920 \\
\hline 7 & 82 & 6,781 & 45,982 & 84 & 6 & 36 & 86 & 5,469 & 29,91 & 6724 & 7056 & 6888 & 7056 & 7396 & 7224 \\
\hline 8 & 85 & 9.781 & 95,668 & 87 & 9 & 81 & 89 & 8,469 & 71.72 & 7225 & 7569 & 7395 & 7569 & 7921 & 7749 \\
\hline 9 & 83 & 7,781 & 60,544 & 85 & 7 & 49 & 88 & 7,469 & 55,70 & 6889 & 7225 & 7055 & 7225 & 7744 & 7480 \\
\hline 10 & 74 & $-1,219$ & 1,48596 & 77 & -1 & 1 & 81 & 0,469 & 0,22 & 5476 & 5929 & 5698 & 5929 & 6561 & 6237 \\
\hline 11 & 80 & 4.781 & 22,858 & 82 & 4 & 16 & 86 & 9,469 & 29.91 & 6400 & 6724 & 6560 & 6724 & 7396 & 7052 \\
\hline 12 & 80 & 4,781 & 22,858 & 82 & 4 & 16 & 83 & 2,469 & 6,096 & 6400 & 6724 & 6560 & 6724 & 6889 & 6806 \\
\hline 13 & 80 & 4,781 & 22,858 & 85 & 7 & 49 & 88 & 7,469 & 55,79 & 6400 & 7225 & 6800 & 7225 & 7744 & 7480 \\
\hline 14 & 86 & 10,781 & 116,23 & 88 & 10 & 100 & 90 & 9,469 & 89,06 & 7996 & 7744 & 7568 & 7744 & 8100 & 7920 \\
\hline 15 & 83 & 7,781 & 60,544 & 85 & 7 & 49 & 87 & 6,469 & 41,85 & 6889 & 7225 & 7055 & 7225 & 7569 & 7395 \\
\hline 16 & 76 & 0,781 & 0,60996 & 80 & 2 & 4 & 83 & 2,469 & 6,096 & 5776 & 6400 & 6080 & 6400 & 6889 & 6640 \\
\hline 17 & 80 & 4,781 & 22,858 & 83 & 9 & 25 & 86 & 5,469 & 29,91 & 6400 & 6889 & 6640 & 6889 & 7396 & 7138 \\
\hline 18 & 87 & 11,781 & 138,792 & 89 & 11 & 121 & 91 & 10,47 & 109,6 & 7569 & 7921 & 7743 & 7921 & 8281 & 8099 \\
\hline 19 & 82 & 6.781 & 45,982 & 85 & 7 & 49 & 87 & 6,469 & 41,85 & 6724 & 7225 & 6970 & 7225 & 7569 & 7395 \\
\hline 20 & 83 & 7,781 & 60,544 & 85 & & 49 & 88 & 7,469 & 59,79 & 6889 & 7225 & 7055 & 7225 & 7744 & 7480 \\
\hline 21 & 75 & $-0,219$ & 0,04796 & 80 & 2 & 4 & 82 & 1,469 & 2,158 & 5625 & 6400 & 6000 & 6400 & 6724 & 6560 \\
\hline 22 & 80 & 4,781 & 858 & 84 & & 36 & 87 & 6,469 & 41,85 & 6400 & 7056 & 6720 & 7056 & 7569 & 7908 \\
\hline 23 & 82 & 6,781 & 45,982 & 89 & 7 & 49 & 88 & 7,469 & 55,79 & 6724 & 7225 & 6970 & 7225 & 7744 & 7480 \\
\hline 24 & 74 & $-1,219$ & 1,48596 & 80 & 2 & 4 & 83 & 2,469 & 6,096 & 5476 & 6400 & 5920 & 6400 & 6889 & 6640 \\
\hline 25 & 82 & 6.781 & 45,982 & 84 & 6 & 36 & 86 & 5,469 & 29,91 & 6724 & 7056 & 6888 & 7056 & 7396 & 7224 \\
\hline 26 & 74 & $-1,219$ & 1,48596 & 77 & -1 & 1 & 81 & 0,469 & 0,22 & 5476 & 5920 & 5698 & 5920 & 6561 & 6237 \\
\hline 27 & 78 & 2,781 & 7,73396 & 80 & 2 & 4 & 83. & 2,469 & 6,096 & 6084 & 6400 & 6240 & 6400 & 6889 & 6640 \\
\hline 28 & 80 & 4,781 & 22,858 & 84 & 6 & 36 & 80 & 9,469 & 29,91 & 6400 & 7056 & 6720 & 7056 & 7396 & 7224 \\
\hline 29 & 80 & 4,781 & 22,858 & 84 & 6 & 36 & 87 & 6,469 & 41,85 & 6400 & 7056 & 6720 & 7056 & 7569 & 7308 \\
\hline 30 & 76 & 0,781 & 0,60996 & 80 & 2 & 4 & 83 & 2,469 & 6,096 & 5776 & 6400 & 6080 & 6400 & 6889 & 6640 \\
\hline 31 & 80 & 4,781 & 22,858 & 83 & 9 & 25 & 86 & 5,469 & 29,91 & 6400 & 6889 & 6640 & 6889 & 7996 & 7138 \\
\hline 32 & 80 & 4,781 & 22,858 & 83 & 3 & 25 & 85 & 4,469 & 19,97 & 6400 & 6889 & 6640 & 6889 & 7225 & 7055 \\
\hline & 2407 & & 1151,7 & 2496 & & 1086 & 2577 & & 1075 & 103510 & 207042 & 2005100 & 207042 & 221193 & 214646 \\
\hline & 75,219 & & 5,9991 & 78 & & 5,83 & 80,531 & & 5,797 & & & & & & \\
\hline & & & & & & & & & & \multicolumn{3}{|c|}{$r=0,798, t=7$, } & \multicolumn{3}{|c|}{$r=0,899, t=11,26$} \\
\hline
\end{tabular}


Berdasarkan tabel di atas diperoleh nilai rata-rata semakin meningkat yaitu : rata-rata tes awal sebesar 75,219, rata-rata tes siklus pertama sebesar 78 rata-rata tes siklus kedua sebesar 80,531. Dan diperoleh nilai simpangan baku semakin menurun yaitu : nilai simpangan baku tes awal (pre tes) sebesar 5,999, nilai simpangan baku tes siklus pertama (ujian blok I) sebesar 5,83, nilai simpangan baku tes siklus kedua (ujian blok II) sebesar 5,797. Berikutnya, diperoleh nilai korelasi semakin meningkat yaitu : nilai korelasi antara tes awal (pre tes) terhadap tes siklus pertama (ujian blok I) sebesar 0,798 dengan nilai uji t sebesar 7,262, dan nilai korelasi antara tes siklus pertama (ujian blok I) terhadap tes siklus kedua (ujian blok II) sebesar 0,899 dengan nilai uji $\mathrm{t}$ sebesar 11,26. Ini semua dikategorikan sangat signifikan. Dan dapat dilihat pada diagram batang tentang perolehan nilai rata-rata semakin meningkat berikut :

Gambar 4. Diagram Batang Nilai RataRata Hasil Belajar Matematika Siswa Kelas IX MTsN 1 Langkat

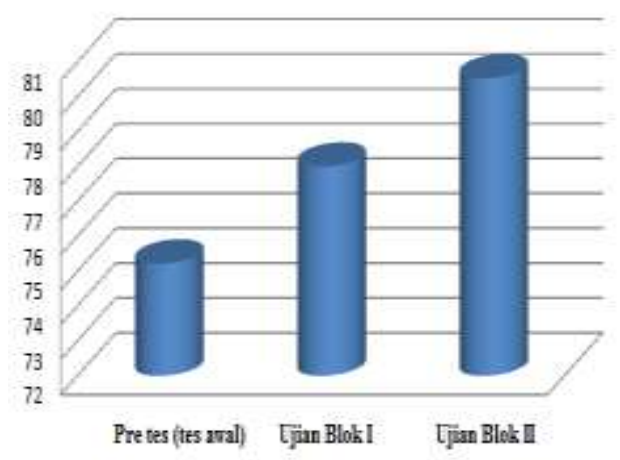

Dan diagram batang tentang perolehan nilai simpangan baku semakin menurun berikut :

\section{Gambar 5. Diagram Batang Nilai Simpangan Baku Hasil Belajar Matematika Siswa Kelas IX MTsN 1 Langkat}

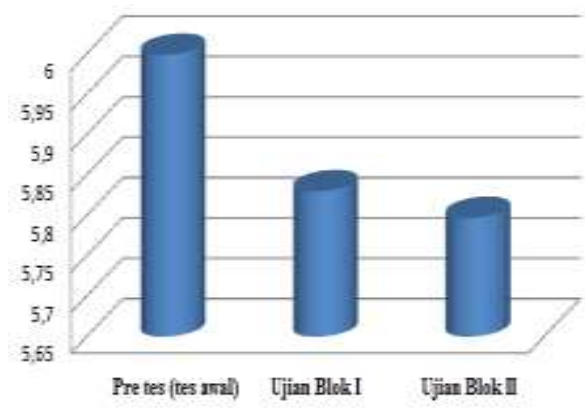

Begitu juga tentang kehadiran para siswa diperoleh nilai kehadiran semakin meningkat yaitu : pada kehadiran awal sebesar $88 \%$, dan pada kehadiran siklus pertama meningkat menjadi 95\%, serta pada kehadiran siklus kedua meningkat menjadi $100 \%$. Ini artinya para siswa semakin aktif dan kreatif dalam mengikuti proses kegiatan belajar mengajar di dalam kelas, karena mereka merasa senang mengikuti pelajaran tersebut. Dan diagram batang tentang perolehan nilai kehadiran siswa dalam mengikuti proses kegiatan belajar mengajar di dalam kelas semakin meningkat berikut :

Gambar 6. Diagram Batang Nilai Kehadiran Aktivitas Belajar Siswa IX MTsN 1 Langkat

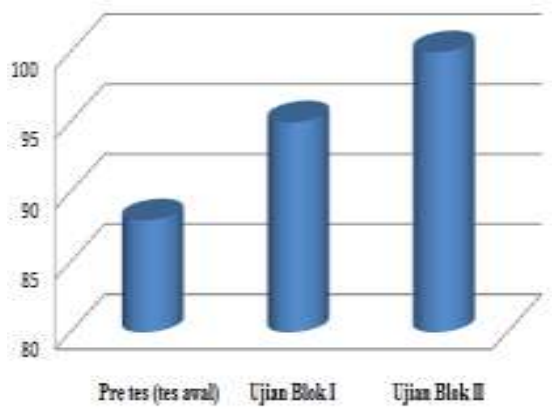


Berdasarkan keterangan hasil penelitian dan pembahasan di atas menunjukkan bahwa Metode Picture And Picture kartu grafik fungsi sebagai media pembelajaran matematika dapat meningkatkan hasil belajar matematika dan aktivitas siswa dalam belajar matematika di kelas IX Madrasah Tsanawiyah Negeri 1 Langkat. Ini artinya metode tersebut sangat tepat dipakai dalam proses belajar mengajar di sekolah.

\section{SIMPULAN}

Penelitian tindakan kelas (PTK) ini memiliki kesimpulan sebagai berikut : Metode Picture And Picture kartu grafik fungsi sebagai media pembelajaran matematika dapat meningkatkan hasil belajar matematika siswa dalam belajar matematika di kelas IX Madrasah Tsanawiyah Negeri 1 Langkat, hal ini dapat dilihat dari nilai korelasi semakin meningkat yaitu : nilai korelasi antara tes awal (pre tes) terhadap tes siklus pertama (ujian blok I) sebesar 0,798 dengan nilai uji t sebesar 7,262, dan nilai korelasi antara tes siklus pertama (ujian blok I) terhadap tes siklus kedua (ujian blok II) sebesar 0,899 dengan nilai uji t sebesar 11,26, serta Metode Picture And Picture kartu grafik fungsi sebagai media pembelajaran matematika dapat meningkatkan aktivitas siswa dalam belajar matematika di kelas IX Madrasah Tsanawiyah Negeri 1
Langkat, hal ini dapat dilihat dari nilai kehadiran siswa dalam mengikuti proses belajar mengajar di kelas semakin meningkat yaitu : pada kehadiran awal sebesar $88 \%$, dan pada kehadiran siklus pertama meningkat menjadi $95 \%$, serta pada kehadiran siklus kedua meningkat menjadi $100 \%$.

\section{DAFTAR RUJUKAN}

Ahmadi, A., dan Supriyono, W. 1993. Psikologi Belajar. Jakarta: Raja Grafindo Persada

Akbar, S. 2013. Instrumen Perangkat Pembelajaran. Bandung: Remaja Rosdakarya.

Arikunto, S. 2003. Prosedur Penelitian, Suatu Pendekatan Praktek. Jakarta : Rineka Cipta.

H., Sigit Suprijanto dkk. 2012, Matematika SMP Kelas IX. Jakarta: Yudistira.

Hamdani. 2011. Strategi Belajar Mengajar. Bandung : Pustaka Setia.

Hadari, Nawawi. 2005. Metodologi Penelitian Tindakan. Yogyakarta: Gadjah Mada University Press.

Slameto. 2010. Belajar dan Faktorfaktor yang Mempengaruhi, Jakarta : Rineka Cipta.

Sardiman, AM. 2011. Interaksi dan Motivasi Belajar Mengajar. Jakarta : Rajawali Pers. 